\title{
Voices of the Caribou People: a participatory videography method to document and share local knowledge from the North American human- Rangifer systems
}

\author{
Archana Bali $^{1,2}$ and Gary P. Kofinas ${ }^{1,2}$
}

\begin{abstract}
Voices of the Caribou People" is a participatory videography project for documenting and sharing the local knowledge of caribou-user communities about social-ecological changes. The project was conducted in partnership with indigenous people who share a long and close relationship with caribou and self-identify as the "Caribou People." The Caribou People desired to share their knowledge, experiences, challenges, and coping strategies with other indigenous communities and with scientists and wildlife managers. Six communities in the North American Arctic participated in the project, with 99 people interviewed about the ecological, cultural, spiritual, and nutritional aspects of their relationship with caribou. The Caribou People wished to tell their stories with their own voices, without the filter of a researcher's interpretations of their messages. The communities defined three project goals, i.e., documentation, communication, and sharing of knowledge, and we identified methodological challenges associated with these goals. Through videography, we sought to overcome these challenges and accomplish community goals, which formed the basis for our project's evaluation. Participants reported changes and concerns ranging from impacts of oil and gas exploration, mining activities, nonlocal hunting, and high energy costs to impacts of climate-related conditions. All interviews were made available in the public domain via the Internet for sharing. In the view of the communities, videography preserved their legacy and served as a repository of traditional knowledge in changing times; visual images were seen as a powerful medium to communicate with policy makers and the public at large and were seen as a preferred informal, unstructured approach. We have (1) described the approach of the Voices of the Caribou People project as a collaborative video methodology and (2) discussed the effectiveness of this method in meeting the goals of participatory research. General insights into the process of using videography as a participatory research tool to study socialecological systems in partnership with indigenous communities have been provided.
\end{abstract}

Key Words: Caribou People; human-rangifer systems; indigenous communities; local knowledge; participatory research; traditional knowledge; videography

\section{INTRODUCTION}

The International Polar Year (IPY) of 2007-2008 was a breakthrough for large-scale Arctic scientific studies because indigenous people of the Arctic were specifically engaged in learning and studying about changes affecting their socialecological systems (Krupnik 2009). Collaborative approaches between indigenous people and researchers are increasingly seen as critical for both (1) the effective documentation of traditional knowledge that provides a long-term baseline information about the past and contemporary social and ecological conditions (Berkes et al. 2000), and (2) the integration of indigenous local knowledge (LK) and scientific research that can address the challenges of rapid environmental and social changes in the Arctic (Moller et al. 2004). Integration of LK with Western scientific methods and findings, however, presents a suite of epistemological, ontological, and practical problems (Berkes 2012).

Some of the barriers in incorporating LK with scientific research and assessments are rooted in the difficulties of accessing such knowledge (Huntington 2000). For example, traditional ecological knowledge (TEK), a component of LK, is passed on as an oral tradition in stories attached to people and events over generations, and contemporary LK is usually shared as stories describing personal experiences. Too often, scientific interpretations of LK are decontextualized, rendering that knowledge as devalued (Cruikshank 1998). Local observations and experiences are embedded in specific contexts, times, and spaces. We regard that context as a critical component of LK in maintaining local community member perspectives, i.e., what is changing, what the effects are, and what people's concerns are, because the knowledge holders are an integral part of the system undergoing change. Consequently, Huntington (2000) urged that LK be documented as a project on its own prior to incorporation into a scientific enterprise; otherwise, the local context and breadth of knowledge would be lost.

We set out to document the context and breadth of the socialecological system encompassing Arctic people and caribou through the Voices of the Caribou People project, hereafter referred to as the "Voices Project," i.e., a picture of the changing Arctic through the eyes of the people of the Arctic (Bali and Kofinas 2008). Human-rangifer systems are the coupled systems of indigenous communities in Alaska and Northern Canada and their traditional subsistence resource, the barren-ground caribou (Rangifer tarandus). The caribou is the most numerous large terrestrial mammal in the Arctic. Many native communities maintain strong nutritional, cultural, and spiritual ties with caribou and identify themselves as the "Caribou People." Although these human-caribou systems have persisted for thousands of years, the living conditions in the present are undergoing rapid change. Over the past 50 years, all major caribou herds in North America have been exposed to industrialization and developmental activities (NRC 2003). In addition to these direct human activities, the North is also faced with rapidly changing climatic conditions (ACIA 2004) and a suite of other

${ }^{1}$ Department of Humans and Environment, School of Natural Resources \& Agricultural Sciences and Institute of Arctic Biology, University of Alaska Fairbanks, ${ }^{2}$ Resilience and Adaptation Program, University of Alaska Fairbanks 
social, economic, and political changes, which have resulted in a high cost of living, changes in the ways caribou are hunted and used, and incidental loss of traditional knowledge.

The Voices Project is a video-based documentation of the indigenous knowledge, observations, and perspectives of the Caribou People, focusing on social-ecological changes as perceived during the IPY. The IPY program is an international initiative at a grand scale both geographically and also in the scope of research themes and diversity. Within such an international program, often there is a risk of local voices getting passed over or lost in the process of knowledge production and broad-scale knowledge synthesis. The Voices Project was an attempt to bring forward the local views and the expression of LK in a multidimensional way and contribute to a circum-Arctic-scale research program. This project was supported by the CircumArctic Rangifer Monitoring and Assessment (CARMA) network as part of their IPY research program. CARMA is a network of researchers, managers, and community people who monitor and share information about the population and status of caribou and how they are affected by global changes (http://www.caff.is/ carma).

The applied objective of our project was to document the local people's experiences of change, perceptions of impacts, and responses to those changes in six communities across the North American Arctic. We also sought to create a living web-based information source of the Caribou People's voices for ongoing contributions and as a lasting legacy of the IPY. We describe the process of carrying out such a large-scale participatory project in a way that is culturally appropriate and sensitive to the spatiotemporal context of the knowledge. From a research perspective, our primary goal was to evaluate if participatory videography was an effective tool for accomplishing both community and science goals and needs. Further, we discuss how we overcame the methodological challenges of accomplishing three specific goals set by the communities for this project: documentation, communication, and the sharing of their perspectives and concerns.

\section{METHODS}

The art and science of documenting $L K$ with videos

In the early 1950s, English anthropologists Gregory Bateson and Margaret Mead (1952) comprehensively demonstrated the utility of film as a research tool with their documentary Trance and Dance in Bali (Lipset 1982). Since then, the popularity and use of film and video as ethnographic tools have grown along with the increasing availability and transportability of equipment (Rosenstein 2002, Lunch and Lunch 2006, Chalfen 2011). Videography has been used for qualitative research, awareness, and advocacy on a wide array of issues including historical documentation (Hartman 1994), human health (Lynagh 2010), language preservation, education and engagement with youth (Gearheard 2005), environmental assessment (Usher 2000), wildlife monitoring and natural resource management (Moller et al. 2004, Branch 2011), and climate change (Cruikshank 2001, Kunuk and Mauro 2010).

Although film has only been recognized as an ethnographic research tool since the $1950 \mathrm{~s}$, its use in documenting indigenous cultures has continued since films were first made (Barbash and
Taylor 1997). In the Arctic, Flaherty's (1922) Nanook of the North began a trend that has continued to the present, where film has found increasing appeal for both engaging indigenous people in shared projects and bringing forth images, albeit contrived in some cases, of the remote indigenous cultures to the mainstream public. Recently, there has been a proliferation of the use of videography to document and communicate indigenous knowledge, especially in the Arctic, so much so that now there are film enterprises owned and operated by several indigenous First Nations. For instance, the Vuntut Gwitchin First Nation from the Yukon Territory, Canada, has been producing documentaries on various oral histories, cultural practices, and cultural geography projects, such as Drymeat Making (Moses 2001), Our History That Binds Us (Kassi 2001), and Imprints of Our Ancestors (Moses and Kassi 2003). The Inuit-owned film production house and TV channel Isuma Productions in Nunavut, Canada, has successfully produced several critically acclaimed films depicting Inuit culture and perspectives, such as Atanarjuat the Fast Runner (Kunuk 2001) and Inuit Knowledge and Climate Change (Kunuk and Mauro 2010).

Moving visual images and sounds bring people and cultures alive onscreen, capturing the living testimony of conditions in a way neither written words nor still photography can. Through contemporary information distribution systems, video also offers the possibility of reaching a far wider audience than academic publications, providing opportunities for engagement with lay as well as scientific audiences (Barbash and Taylor 1997). For these reasons, videos offer ideal opportunities for the more complete archiving of language, culture, and the context in which people lived.

Most importantly, ethnographic video allows subjects of films to judge the ethnographer's representation of them, i.e., the culture, people's experiences, and their personal stories, in relation to specific questions and context. Hence, the process of video ethnography is a very challenging undertaking and also a twoway learning experience. This is perhaps even more important in a collaborative project, where participants are actively engaged partners, as opposed to being seen just as the "subject" of research.

\section{Capturing "Voices of the Caribou People"}

During the 2007 annual gathering of CARMA network members in Vancouver, British Columbia, Canada, indigenous participants expressed a desire to be more involved in CARMA research. In particular, they asked that their perspectives concerning the broader social-ecological context be included in the existing biophysical research program on caribou. In response to this request, we proposed a project to document the perspectives of the indigenous Caribou People of North America using videography. The indigenous participants received this suggestion with enthusiasm, and the Voices Project was initiated.

We used participatory videography, also referred to as collaborative or engaged filmmaking, a process in which the filmmaker engages "subjects" in deciding what story will be told, how, and to whom (Stiegman and Pictou 2010). More simply, participatory videography is a method to make a video with, not just about, people. The level of participant engagement in this type of effort may take on a spectrum of options; on one end, subjects may work with a director to create films about themselves, 
Table 1. Participant-defined goals and literature-based challenges for accomplishing those goals. Our criteria for evaluation of Voices of the Caribou People Project were how successfully we (1) overcame the challenges and (2) accomplished community goals.

Objectives of Voices of the Caribou People project based on the indigenous participants' goals:

Methodological and philosophical challenges identified in documenting and communicating local knowledge through participatory videography:

Document the Caribou People's local knowledge and observations about Participatory research: research fatigue, respondent burn out (Cullen the changes taking place in their Human-Rangifer Systems to create a 2010, Moerlein and Carothers 2012). repository of knowledge for the communities and their future generations.

Communicate the Caribou People's stories and perspectives with the outside world to inform the policy makers, northern researchers, and public at large about conditions in these Human-Rangifer Systems during the current International Polar Year (IPY).
TEK-related research: Deconstruction and/or fragmentation of knowledge, and danger of imposing nonlocal construct (Cruikshank 1998, Huntington 1998, 2000).

Facilitate sharing of the Caribou People's local knowledge and concerns Videography method: Technical and logistical challenges. to other northern communities faced with similar conditions and challenges to create a platform to share the strategies for coping with changes between communities.

or on the other end, subjects may make their own films. In the Voices Project, we took on the role of facilitator/filmmaker and worked in consultation with the community members to film what they felt were the important aspects of their lives to be shared. Several intermediate and final products were mutually agreed on for accomplishing participants' expectations, including products for the communities as well as products for wider distribution.

\section{Framework for a post hoc review of the Voices Project's participatory videography approach}

\section{Participants' performance measures}

A prerequisite for meaningful partnership between the researcher and the participants is the need to recognize and include participants' goals in the project, i.e., the type of knowledge produced and its relevance to the participants (Wallerstein and Duran 2003). Through shared goals, tangible outcomes of such collaboration can be identified, agreed on, and achieved through establishing trust, assuring participation, and the sharing of power with communities and participants (Israel et al. 1998). However, establishing and maintaining trust and respect, creating a shared purpose, and maintaining engagement and participation have also been identified as the main challenges of participatory research at the same time (Wallerstein and Duran 2003, Cargo and Mercer 2008).

Voices Project objectives were based on needs expressed by the indigenous participants. The participants wanted their knowledge and observations to be included in CARMA's IPY research project and their perspectives to be highlighted. In these times of rapid and dramatic social-ecological change, they wanted their traditional knowledge to be documented to preserve it for future generations. They recognized that other Arctic communities are faced with similar challenges, so they expressed interest in learning from each other, i.e., sharing with other communities about their conditions and challenges and how they are responding to those conditions. Thus, the project objectives (Table 1) served as a primary set of measures to assess how well our process performed in meeting with the project's goals, forming successful partnerships, and producing the outcomes desired by the participants.

\section{Overcoming methodological challenges}

We had set out to document and communicate LK using videography as a tool; therefore, overcoming the practical and philosophical challenges articulated in the literature on methods of participatory videography and documenting LK became our secondary goal (Table 1). Concerns pertaining to appropriate use of videography in social science research include issues of data ownership and availability (Albrecht 1985), as well as interpretation and representativeness (Prosser 1998). All these challenges collectively apply to participatory videography, which is frequently critiqued as a problematic method because of inadequately addressing these challenges (Rodriguez 2001). However, there are few explicit guidelines of what constitutes "good practice" in the use of videography in a cross-cultural context (Chalfen 2011). Similar challenges are also inherent in the documentation and application of indigenous knowledge systems and are again related to access, interpretation, and dissemination of the knowledge (Cruikshank 1998, Huntington 2000, Rosenstein 2002, Berkes 2012). Collectively, these participantdefined and literature-based criteria allowed us to conduct the post hoc assessment of the Voices Project's performance.

\section{The process of the Voices Project}

\section{Introduction}

From conceptualization to execution, the Voices Project took more than 4 years. The project was conceptualized in 2007 , formally initiated in 2008, and now functions as a fully developed, ongoing process (Fig. 1, Table 2). We started the project by inviting a large suite of about 50 organizations of indigenous communities that traditionally subsist on caribou to participate in the North American effort. This included all the communities with preexisting relationships with the CARMA network, to represent the Caribou People throughout the range of the North American human-rangifer system. Information flyers with the project's intention were disseminated via regional caribou comanagement 
Table 2. The main steps in the process and important tasks of each step, as identified by the Voices Project.

\section{PLANNING STAGE:}

Conceptualize the project strategy: Initiate the project by contacting the communities of caribou-users in Alaska and Northern Canada, to invite them to participate in the project.

\section{OBTAINING COMMUNITY APPROVALS \& RESEARCH LICENSES:}

Coordinate process of application for obtaining required permissions and research licenses from all applicable agencies: Institutional Review Board (IRB) at the University; various provincial institutions in Canada and consultations with each of the participating communities and project approvals from respective First Nation Tribal Governments.

\section{FIELD WORK:}

Work with the participating community residents (or collaborating local agencies?) to video-document interviews of community members. This included coordinating the logistics and carrying out the fieldwork: contacting interviewees, conducting and video-recording interviews, providing for translators wherever required, transcription of translated. The interviewees included elders, active hunters, community leaders, women, and children and they talked about the importance of caribou for them and the changes as observed by them.

\section{LAB WORK:}

Digitize footage. This means transferring all footage from the tapes on to hard drives in a digital format. This is used for creating and editing videos.

\section{INFORMATION DISSIMINETAION:}

To archive the video interviews on the Internet, making them freely available in the public domain. To send all the video material back to each of the participating communities and copies of video to respective participants.

\section{FUTURE:}

To create one consolidated documentary on summary of the North American perspectives. To extend the project to include indigenous communities from Greenland, Russia, and others interested.

boards, indigenous organizations, biologists and researchers, and environment and natural resource agencies in Alaska and Canada. Six indigenous communities, 1 in the United States and 5 in Canada, consented to collaborate: Anaktuvuk Pass, Alaska, USA; Old Crow, Yukon Territory, Canada; Wekweeti and LutselK'e, Northwest Territories, Canada; Arviat, Nunavut, Canada; and Kawawachikamach, Quebec, Canada (Fig. 2, Table 3).

All communities were north of 55 degrees latitude, with Anaktuvuk Pass and Old Crow located above the Arctic Circle. None has road access, so primary access to urban centers and their services is by air, although some communities have seasonal boat/snowmobile access. Kawawachikamach has limited rail connections to a few cities. All communities have been seasonally nomadic in the past but settled at different points in history. Old Crow has the oldest history of settlement in its current location since the 1870 s, whereas the Kawawachikamach settlement was established only recently in 1981. All community settlements were strategically located around caribou ranges or migration routes of one or more herds. Once participating communities were identified, we started a dialogue to understand community expectations of the project and planning logistics and "how-to."

\section{Seeking and forming partnerships}

To conduct this project, we needed research permits and community approvals at various levels. For instance, in the United States, an institutional review board (IRB) committee is responsible for approving, monitoring, and reviewing all research involving human participants. In Canada, instead of a centralized agency, we needed to work with each First Nation tribal government as well as respective academic research license granting institutions. In addition to the Human Subjects Review
Fig. 1. Process flow diagram for the Voices Project. Details of activities involved at each stage are provided in Table 2.

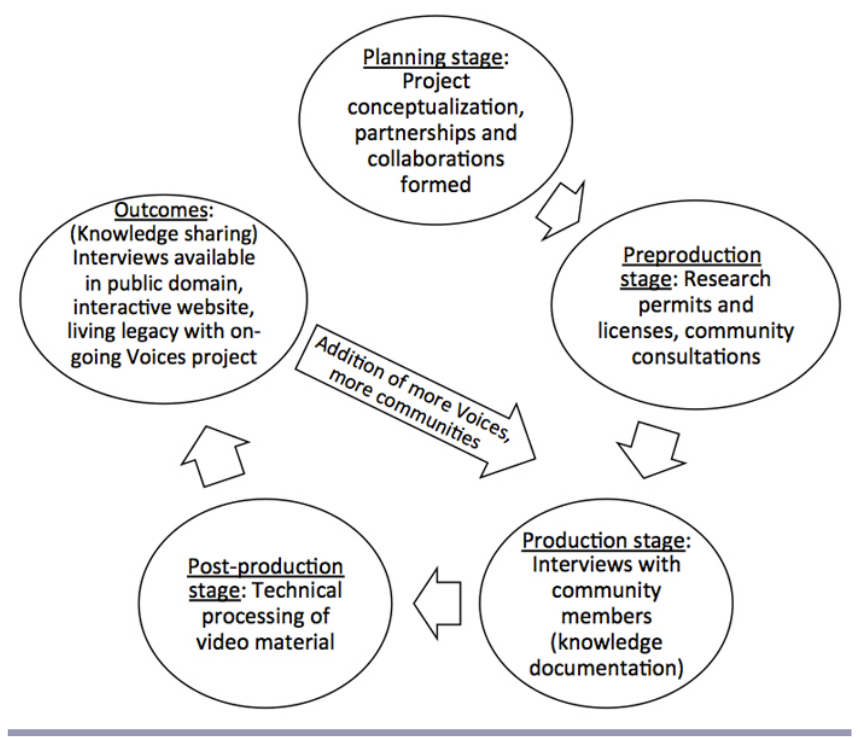

Board at our institution, the University of Alaska Fairbanks, a total of 10 permits were required, involving communications from the territorial to the local level. We ensured throughout the process that project goals and the active participation of the communities were compatible with the ethical requirements of IRBs. We sought informed consent from the participants in every case, making them fully aware of the project's goals and outcomes, and of public 
Fig. 2. Map showing the six participating communities of the Voices of the Caribou People project along with the ranges of North American caribou herds (Adapted from Gunn et al. 2011).

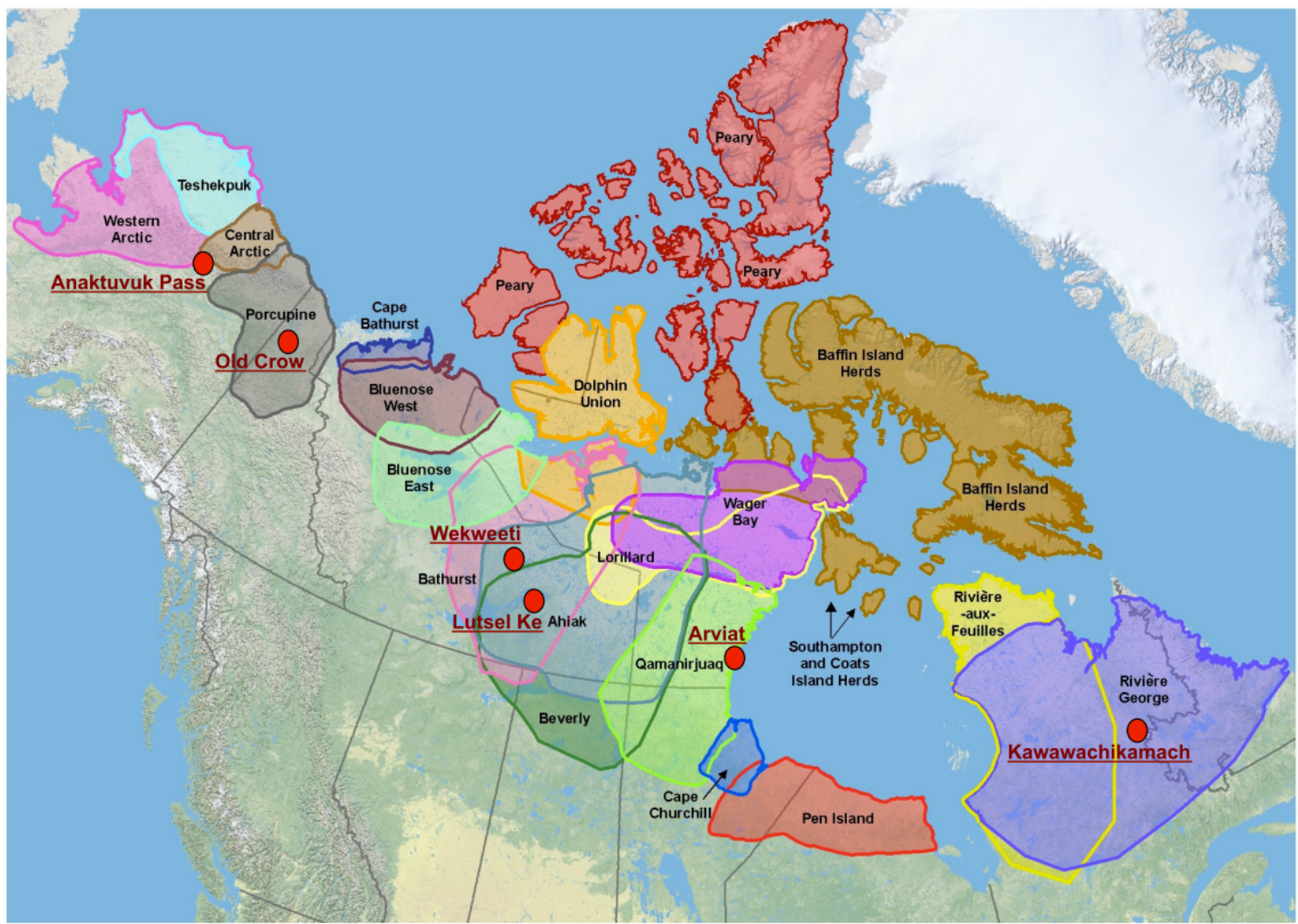

dissemination of all the material without any modification from our side, unless the community or the participant desired otherwise.

After necessary permissions were obtained, we identified one local organization in each community that would become the project's point of contact and collaborator and take primary responsibility for guiding and coordinating the Voices Project in the community. Our project's organizational collaborators included Anaktuvuk Pass Simon Paneak Museum, Old Crow Vuntut Gwitchin First Nations organization, Community Government of Wekweeti, LutselK'e Dene Band, Arviat HunterTrappers Organization, and Naskapi Hunter-Trappers Organization. CARMA provided each collaborator funds, a maximum of US $\$ 5000.00$ per community, to cover direct costs and honorarium for participants, based on local institutional norms. In each community, we entered into a "memorandum of understanding" with the collaborating agencies, thus creating a mutual agreement of what would be done and how. We agreed a priori that all videos would be made available in the public domain without critique or modification from our side, and neither CARMA nor any other organization would profit financially from the project.

\section{The filming}

Fieldwork was conducted from May to August 2008. Field visits in each community were for approximately 15 days. We video recorded people's knowledge and observations of changes taking place on their homelands and in their communities' ways of life, and how these changes are affecting their traditional culture. Our partner community organizations identified prospective interviewees broadly classified as follows: (1) elders, i.e., community residents who were considered LK holders, experienced in traditional activities, and long-term residents in the community; (2) leaders, i.e., elected representatives such chief, member of the legislative assembly, mayor, or village council member; (3) active hunters, i.e., those who actively engaged in caribou subsistence hunting activities; and (4) youth, i.e., young members and children, who were included wherever possible. We sought to include women representatives in all categories to bring out a comprehensive understanding of community perspectives.

The interviews and filming were carried out by Archana Bali with the assistance of at least one local representative in each community. The local assistants were assigned by the collaborating organizations to help meet the communities' criteria of their knowledge documentation. The methods of interviews ranged from semistructured with open-ended questions to spontaneous conversations where the respondents talked about issues that they felt were important to share. The participants were aware that the project was focused around their knowledge and issues related to caribou and people, but they were given freedom to talk about any issues of interest and concern to them. This 
Table 3. Profile information on the six participating communities representing heterogeneous social-ecological conditions.

\begin{tabular}{|c|c|c|c|c|c|c|}
\hline $\begin{array}{l}\text { Community } \\
\text { name }\end{array}$ & $\begin{array}{l}\text { Anaktuvuk Pass, } \\
\text { (Alaska) }{ }^{\dagger}\end{array}$ & $\begin{array}{l}\text { Old Crow } \\
\text { (Yukon }^{\ddagger} \\
\text { Territory) }\end{array}$ & $\begin{array}{l}\text { Wekweeti (Northwest } \\
\text { Territory) })^{\S, 1}\end{array}$ & $\begin{array}{l}\text { Lutsel' Ke } \\
\text { (Northwest } \\
\text { Territory) }\end{array}$ & Arviat (Nunavut) & $\begin{array}{l}\text { Kawawachi-kamach } \\
\text { (Quebec) }^{\dagger \dagger}\end{array}$ \\
\hline Tribe & $\begin{array}{l}\text { Nunamiut Eskimo } \\
\text { (inland Eskimos) }\end{array}$ & $\begin{array}{l}\text { Vuntut } \\
\text { Gwitch'in } \\
\text { (people of the } \\
\text { lakes) }\end{array}$ & Tlicho (Dogrib, Dene) & Chipewyan, Dogrib & Inuit (Eskimo) & Naskapi (Iyiyiw) \\
\hline Language & Inupiat & $\begin{array}{l}\text { Gwitch'in } \\
\text { Athapaskan }\end{array}$ & $\begin{array}{l}\text { Tlicho } \\
96 \% \text { population speak } \\
\text { the aboriginal } \\
\text { languages }\end{array}$ & $\begin{array}{l}\text { Chipewyan } \\
77 \% \text { population } \\
\text { speak the native } \\
\text { language }\end{array}$ & $\begin{array}{l}\text { Inuktitut } \\
93 \% \text { population } \\
\text { speak the native } \\
\text { language }\end{array}$ & $\begin{array}{l}\text { Naskapi } \\
\text { vast majority of } \\
\text { community } \\
\text { members speak } \\
\text { Naskapi. }\end{array}$ \\
\hline Population size & $\begin{array}{l}324(2010), 84 \\
\text { households }\end{array}$ & $\begin{array}{l}267 \text { (2008), } \\
118 \text { households }\end{array}$ & $\begin{array}{l}145(2011), \\
35 \text { households }\end{array}$ & $\begin{array}{l}310(2011), \\
90 \text { households }\end{array}$ & $\begin{array}{l}2060(2006), \\
450 \text { households }\end{array}$ & $\begin{array}{l}643(2010) \\
134 \text { households }\end{array}$ \\
\hline Settlement size & $12.7 \mathrm{Km}^{2}$ & $14.15 \mathrm{~km}^{2}$ & $14.66 \mathrm{~km}^{2}$ & $43.01 \mathrm{~km}^{2}$ & $132 \mathrm{~km}^{2}$ & $41.44 \mathrm{~km}^{2}$ \\
\hline Geography & $\begin{array}{l}\text { Lat: } 68^{\circ} 08^{\prime} \mathrm{N} \text {, } \\
\text { Elevation: } 670 \mathrm{~m} . \\
\text { Located in the } \\
\text { Brooks range in } \\
\text { Alaska's north } \\
\text { slope. }\end{array}$ & $\begin{array}{l}\text { Lat: } 67^{\circ} 34^{\prime} \mathrm{N} \text {, } \\
\text { Elevation: } 250 \\
\text { m. Northern } \\
\text { most community } \\
\text { in YT, situated } \\
\text { by the Porcupine } \\
\text { river. }\end{array}$ & $\begin{array}{l}\text { Lat: } 64^{\circ} 11^{\prime} \mathrm{N} \text {, } \\
\text { Elevation: } 368 \mathrm{~m} \text {. } \\
\text { Located on the north } \\
\text { shore of Great Slave } \\
\text { lake, } 195 \mathrm{~km} \text { north of } \\
\text { Yellowknife, the } \\
\text { capital of NWT. }\end{array}$ & $\begin{array}{l}\text { Lat: } 62^{\circ} 24^{\prime} \mathrm{N} \text {, } \\
\text { Elevation: } 168 \mathrm{~m} \text {. } \\
\text { Located on the East } \\
\text { Arm of Great Slave } \\
\text { Lake, } 201 \mathrm{~km} \text { east of } \\
\text { Yellowknife. }\end{array}$ & $\begin{array}{l}\text { Lat: } 61^{\circ} 06^{\prime} \mathrm{N} \text {, } \\
\text { elevation } 10 \mathrm{~m} . \\
\text { Located on the } \\
\text { western shore of } \\
\text { Hudson Bay. }\end{array}$ & $\begin{array}{l}\text { Lat: } 54^{\circ} 52^{\prime} \mathrm{N} \text {, } \\
\text { Elevation: } 580 \mathrm{~m} . \\
\text { Located } 16 \mathrm{~km} \\
\text { northeast of } \\
\text { Schefferville, on the } \\
\text { Quebec-Labrador } \\
\text { border. }\end{array}$ \\
\hline $\begin{array}{l}\text { History of } \\
\text { establishment }\end{array}$ & $\begin{array}{l}\text { The nomadic } \\
\text { Nunamiut moved } \\
\text { to the current } \\
\text { location in 1949. In } \\
\text { 1951, a post office } \\
\text { was established and } \\
\text { the former } \\
\text { settlement was } \\
\text { incorporated in } \\
\text { 1959. }\end{array}$ & 1870. & $\begin{array}{l}\text { Wekweeti was an } \\
\text { outpost hunting camp } \\
\text { until 1962. The } \\
\text { community was } \\
\text { founded when the } \\
\text { Tlicho elder and } \\
\text { former chief Alexis } \\
\text { Arrowmaker brought } \\
\text { several families from } \\
\text { Behchoko who wanted } \\
\text { a more traditional } \\
\text { lifestyle. }\end{array}$ & $\begin{array}{l}\text { Lutsel' Ke was set up } \\
\text { as the Hudson Bay } \\
\text { Company Post in } \\
\text { 1925. In 1954, homes } \\
\text { were moved to the } \\
\text { current site and in } \\
1960 \text { a school was } \\
\text { built. }\end{array}$ & $\begin{array}{l}\text { The Hudson Bay } \\
\text { Company } \\
\text { established a } \\
\text { trading post at } \\
\text { Arviat in the } 1920 \mathrm{~s} \text {. } \\
\text { The area had } \\
\text { previously been } \\
\text { used by the Inuit to } \\
\text { hunt for seals, } \\
\text { walrus, and whales. } \\
\text { In } 1957 \text { because of } \\
\text { starvation, other } \\
\text { inland Inuit bands } \\
\text { were relocated to } \\
\text { Arviat by the Royal } \\
\text { Canadian Mounted } \\
\text { Police. }\end{array}$ & $\begin{array}{l}\text { Formally settled in } \\
\text { Kawawachikamach } \\
\text { in } 1981 . \\
\text { Originally from } \\
\text { northern Quebec, } \\
\text { the Naskapi were } \\
\text { subjected to several } \\
\text { relocations before } \\
\text { moving to recently } \\
\text { founded iron-ore } \\
\text { mining community } \\
\text { of Schefferville in } \\
\text { 1956. In } 1978 \text { they } \\
\text { acquired the } 41 \mathrm{~km}^{2} \\
\text { of land from } \\
\text { Quebec government } \\
\text { and built the village } \\
\text { of } \\
\text { Kawawachikamach. }\end{array}$ \\
\hline Economy & $\begin{array}{l}\text { Subsistence hunting } \\
\text { and trapping for } \\
\text { food and clothing. } \\
\text { Fur sale, sale of } \\
\text { traditional caribou } \\
\text { skin masks. Some, } \\
\text { limited, outside } \\
\text { seasonal } \\
\text { employments. }\end{array}$ & $\begin{array}{l}\text { Main source of } \\
\text { livelihood is } \\
\text { hunting trapping } \\
\text { and fishing. }\end{array}$ & $\begin{array}{l}\text { Subsistence hunting, } \\
\text { trapping, fishing. } \\
\text { Produce art and craft, } \\
\text { jobs in the diamond } \\
\text { mines and seasonal } \\
\text { jobs outside town. }\end{array}$ & $\begin{array}{l}\text { Subsistence hunting, } \\
\text { trapping, fishing. } \\
\text { Jobs in the diamond } \\
\text { mines, outfitting for } \\
\text { hunting and sport } \\
\text { fishing, arts and } \\
\text { crafts }\end{array}$ & $\begin{array}{l}\text { Hunting and } \\
\text { fishing. Well known } \\
\text { for art and craft, } \\
\text { and music talent }\end{array}$ & $\begin{array}{l}\text { Hunting, fishing, } \\
\text { trapping, arts and } \\
\text { crafts, tourism, } \\
\text { outfitting, and } \\
\text { construction work. }\end{array}$ \\
\hline Income & $\begin{array}{l}\text { Mean annual per } \\
\text { capita income } \\
\$ 15,200(2007) \\
4.4 \% \text { of population } \\
\text { below poverty line. }\end{array}$ & $\begin{array}{l}\text { Mean annual } \\
\text { household } \\
\text { income } \$ 28,244 \\
(2006)\end{array}$ & $\begin{array}{l}\text {-- } \\
\text { Information Not } \\
\text { Available }\end{array}$ & $\begin{array}{l}\text { Mean annual } \\
\text { household income } \\
\$ 58,611 \text { (2009) }\end{array}$ & $\begin{array}{l}\text { Median annual } \\
\text { household income } \\
\$ 45,184 \text { (2006) }\end{array}$ & $\begin{array}{l}\text { Median annual } \\
\text { household income } \\
\$ 45,312(2005)\end{array}$ \\
\hline \multicolumn{7}{|c|}{ 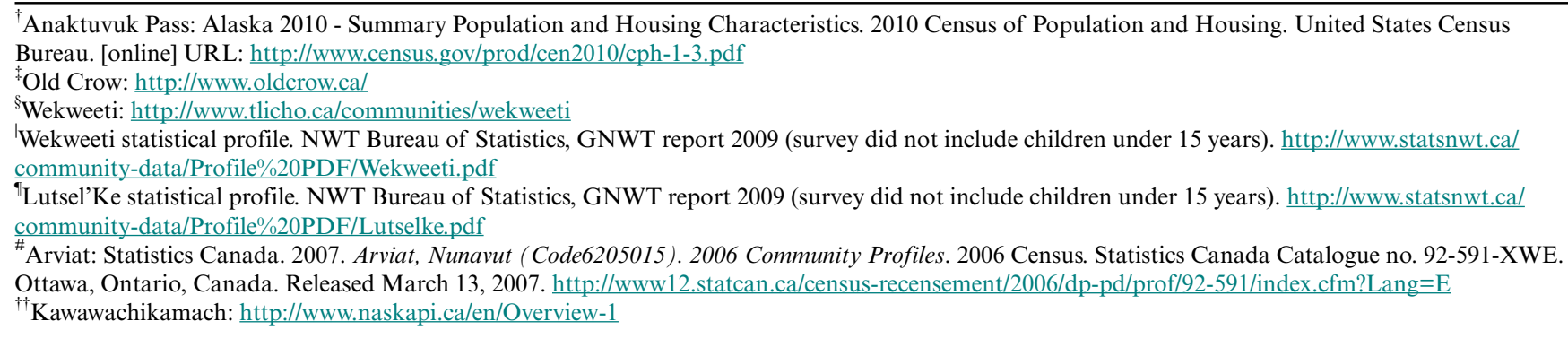 } \\
\hline
\end{tabular}


approach provided flexibility and freedom to the participants to express their own stories, in the way they felt they should be told (Huntington 1998). For non-English-speaking participants, translators were provided. The interviews were recorded as either one-on-one conversations with the researcher-filmmaker or as conversations between two or more people.

We interviewed 20-24 residents in each community. Videos included traditional subsistence-related activities, such as hunting, fishing, and gathering, processing of native foods, and arts and crafts making; and recreation activities, such as storytelling, dancing and drumming, and potlucks. Knowledge on traditional activities such as native foods preparation, processing of meat for long-term storage, and processing caribou hides was documented. Individuals' stories, legends, and songs were also recorded.

\section{The outcomes of the Voices Project}

\section{Postfilming and end products}

A total of 99 interviews resulting in more than 120 hours of video data were collected. The postproduction process included three phases: (1) technical work, i.e., converting raw data into finished products; (2) products for communities, i.e., sharing the products with the communities; and (3) living voices, i.e., making the products available to a wider audience via the Internet.

Phase 1 included digitization of all video material, editing raw footage to create movie files for each interview. We used the program FinalCutPro for editing and producing movie files of each interview. Additionally, interviews in native languages were translated and transcribed in English. The task of translation and transcription was most time intensive and one of the greatest challenges of the project. Our arrangement with communities was to provide an unabridged version of their interviews; in other words, nothing was to be modified or left out. Hence, our primary role as editors was to render the interviews into a consistent and finished form. The first phase proved to be the most timeconsuming and technically intensive part of the project.

In phase 2, we sent all the documented information back to the individual participants from each community to accomplish the Voices Project's first objective. These interviews, finished as easyto-view movie files, were sent to each participant in the form of a DVD. Each of the participating communities received the entire set of videos filmed in its village, as a repository of its LK recorded during IPY 2007-2008. To meet the second objective, to generate interest about the project and spread awareness about the lives of the Caribou People, we created short thematic films. Several versions of the video documentary Voices of the Caribou People have been produced since 2008. These short films were intended for distribution to communities, libraries, schools, museums, and cultural centers. They have also been presented at IPY meetings and other scientific conferences as a form of outreach to the scientific community. Versions of this film have also been screened at several film festivals in United States, Canada, and other countries and have won two awards, including the International IPY Student Video Contest (2008).

To accomplish the third objective, phase 3 was focused on wider outreach using the Internet as a medium. An interactive web archive, containing the entire set of videos gathered, is publicly available on the website http://voicesproject.caff.is/ and is easily accessible to the communities, Arctic researchers, and a wider audience via the Internet and linked through the CARMA website. Since 2008, more communities in Alaska, Canada, Greenland, and Russia that depend on caribou and wild reindeer have expressed an interest in being included in the Voices Project. We are working toward making the website an ongoing project, where in the future community members can create their own videos and post their voices to the project's website. Because LK is dynamic in nature over space and time (Berkes 2012), this website would be a true legacy of the IPY program, a snapshot of conditions during 2007-2008, and serve as baseline information for future comparisons. Phases 1 and 2 are complete, and phase 3 will continue on as "living voices," to provide a continuing and locally based record of important issues concerning the humancaribou systems.

\section{A synopsis of the Voices Project}

In all communities, participants talked about cultural, spiritual, and nutritional dependence on caribou, observations of changes, and concerns about sustaining caribou in the future. The elders spoke about long-term changes in lifestyles, caribou hunting and usage, and changing climatic conditions as they experienced during their lifetime. Elders explained the traditional methods of hunting caribou and living off the land and contrasted what they viewed as their traditional, more resilient lifestyle with the modern one where their ability to hunt caribou depends on economic factors. Hunters spoke about their needs for caribou and current conditions on the land, as well as the difficulties they face while harvesting caribou. Hunters also shared their knowledge on how caribou movements, body condition, and numbers have fluctuated over time in their regions, and how the animals might be affected by climate-related or anthropogenic disturbance such as roads and mines. Leaders talked about the major political challenges their communities face and their strategies to respond to those challenges. They also talked about the communities' needs for information and assistance from scientists and agencies to adapt to the changes. The youth spoke about the importance of caribou in their life and their future aspirations. They talked about their experience on land and involvement in traditional activities, such as hunting, fishing, arts and crafts making, and consumption of native foods.

We found several commonalities between these communities in the nature of the challenges they are facing. These challenges include the ubiquitous problem of the high cost of living in remote Arctic areas, which is largely attributed to high energy costs; greater extractive development activities in homelands; and social challenges of integration with modern society and problems of engaging youth in traditional pursuits. Voices Project participants also talked about the effects of climate change, although the concern about climate change varied in importance as compared with social and economic issues.

\section{Summary of challenges faced by the six communities}

Caribou are very important to the last remaining Nunamiut of Anaktuvuk Pass, but there is a very high rate of unemployment and very limited economic opportunities in this isolated community. As a result, the community was torn about whether to support oil and gas exploration activities in their region, which they were concerned would affect their caribou herds' movements but also create job opportunities for the community members. In 
Table 4. A performance evaluation of the Voices of the Caribou People project. TEK = traditional ecological knowledge.

\begin{tabular}{|c|c|c|}
\hline Objectives & Opportunities & Challenges \\
\hline $\begin{array}{l}\text { Documentation and preservation of the } \\
\text { community's TEK }\end{array}$ & $\begin{array}{l}\text { Videos provide a useful and easy medium to document } \\
\text { local knowledge. Videos align with how indigenous } \\
\text { people teach and learn, by watching, listening, speaking, } \\
\text { and following. The Voices Project was able to engage } \\
\text { men and women of all three generations alike to share } \\
\text { their knowledge and experiences. } \\
\text { Each community received a set of DVDs containing all } \\
\text { the material contributed by their members. }\end{array}$ & $\begin{array}{l}\text { Lack of willingness to participate due to time } \\
\text { conflict with subsistence or other activities. } \\
\text { Hesitation in participation due to research } \\
\text { fatigue and respondent burnout. } \\
\text { Likely to face difficulties in gaining trust due to } \\
\text { "lack of reporting the research findings back to } \\
\text { the communities" from previous research } \\
\text { projects that were conducted in the } \\
\text { communities. }\end{array}$ \\
\hline $\begin{array}{l}\text { Communication of the communities } \\
\text { TEK and outreach }\end{array}$ & $\begin{array}{l}\text { Participatory videography is empowering to the } \\
\text { communities because the process puts emphasis on the } \\
\text { participants. The video content presents participants' } \\
\text { point of view, opinion, and belief as a form of bearing } \\
\text { witness and making a testimony. } \\
\text { While communicating indigenous knowledge systems, } \\
\text { there is a danger of deconstructing and misinterpreting } \\
\text { an information piece when it is presented out of } \\
\text { context. The unabbreviated videos in Voices Project help } \\
\text { preserve the relevant context. }\end{array}$ & $\begin{array}{l}\text { Challenges related to sensitivity of indigenous } \\
\text { knowledge and stories to misinterpretation, and } \\
\text { issues pertaining to access and dissemination of } \\
\text { the indigenous intellectual property highlighted } \\
\text { in literature. } \\
\text { In certain cases, there was hesitation in sharing } \\
\text { certain stories and observations because of the } \\
\text { communities' ongoing land claims negotiations } \\
\text { with the government agencies. }\end{array}$ \\
\hline $\begin{array}{l}\text { Sharing of the Voices by making the } \\
\text { videos freely accessible in the public } \\
\text { domain }\end{array}$ & $\begin{array}{l}\text { The internet provides a great platform for facilitating } \\
\text { the information sharing. } \\
\text { Resolves the issues of data ownership and access. }\end{array}$ & $\begin{array}{l}\text { Issues of data ownership needed to be } \\
\text { addressed and resolved a priori. } \\
\text { Multiple technical challenges related to } \\
\text { filmmaking and making large video datasets } \\
\text { available through the Internet. }\end{array}$ \\
\hline
\end{tabular}

addition, the community voiced concern about the effects of lowflying aircraft around caribou and competition from nonlocal hunters.

The Vuntut Gwitchin of Old Crow were very concerned about the future of the Porcupine caribou herd and noted the link between caribou and their own future. The main threat to the Porcupine caribou was thought to be from potential oil and gas development in the Arctic National Wildlife Refuge, and for past two decades, without failure their representatives have been participating in the lobbying efforts in Washington, D.C., to avoid development within the refuge. In addition, they have systematically observed dramatic changes in environmental conditions over the past few years, which they attribute to the significant impacts on caribou movement patterns.

The Tlicho of Wekweeti subsist mainly on the Bathurst caribou herd. Right in the middle of a narrow section of the migration path of the Bathurst herd, there are four diamond mines. The people of Wekweeti suspect several adverse impacts of the mining and related activities on their caribou's food, health, and movement.

The LutselK'e people share similar concerns as Wekweeti members because they also subsist on the Bathurst herd. They also face competition from outfitters and nonlocal hunters when seeking to meet their subsistence requirements. The community is engaged in land-claim agreements and voiced needs for more information and support from agencies and researchers to make decisions regarding their resources.

Arviat, located in the newest Canadian territory of Nunavut, where only 30,000 people live in 2 million $\mathrm{km}^{2}$ of wilderness, are faced with a lack of adequate infrastructure and employment options. The community faces the dilemma of trade-offs between strict protection for their land and resources, i.e., calving grounds and migration paths of the Qamanariaq caribou herd, versus support for proposed uranium and other mining industries, similar to the dilemma faced in Anaktuvuk Pass with oil development.

The Ungava region in northern Quebec where Kawawachikamach is located has a long history of mining and exploration. The Naskapi people voiced their concerns about climate change effects and the disturbance on land from mining operations affecting the availability and accessibility of the George caribou herd to their people. They talked about seasonal changes resulting in early springs and rapid river breakups with negative effects on hunting and fishing. They had to hire airplanes to go hunting, which was both expensive and did not provide enough traditional food.

\section{DISCUSSION}

\section{A post hoc assessment of the Voices Project}

In the literature, videography is touted as an extremely powerful tool for enabling community members to document their way of life through a relatively unfiltered method. Such videos provide the participants with a way to not only educate their own future generations but also inform outsiders about their knowledge, culture, and way of life (Barbash and Taylor 1997, Gearheard 2005, Cullen 2010, Branch 2011, Chalfen 2011). Our experience confirmed this finding. During the filming, several opportunities or challenges were articulated by community participants specifically related to using video as a tool for documenting and accessing their LK. In considering the effectiveness of this project, we discuss the project's performance at accomplishing the participants' objectives and addressing the methodological barriers (Table 4). 
Documentation and preservation of the community's TEK

As for other researchers, we confirmed that the use of video is a useful and easy method to preserve and access community knowledge because the audiovisual medium aligns with how indigenous people teach and learn, by watching, listening, speaking, and following (Gearheard 2005, Branch 2011). This finding was reflected in the experience of Voices Project participants as well. Our process was consistent with the idea of an engaged videography (Chalfen 2011) that involved a collaborative process to formulate the right questions, appropriate themes, and content to document. In their comprehensive review, Cargo and Mercer (2008) highlighted self-determination, the capacity of individuals and groups to chart their own courses, as an important prerequisite for the appropriate participation. The decisions were made in a collaborative process and evolved as the partners deemed appropriate. For instance, who should participate and how they should participate were left to community organizations to decide. As participatory videographers interested in an ethnographic account, we recognized the need to develop mutual trust and understanding with the participants and the importance of their discretion in deciding what parts of their lives they wanted to share and how (Stiegman and Pictou 2010).

The participants also acknowledged the important role that this methodology serves in archival of LK in a community's own words; videotaped information will serve their communities as a repository of traditional ways, in the changing times. They also recognized that videos effectively engaged the young members of the communities. Distinct from other methods that often focus on a researcher's own specific interests, this format includes a wide swath of information that may serve the communities and other researchers into the future.

A major prerequisite in making this partnership successful was the active and engaged participation by community members. All fieldwork took place during the summer months. As a result, the timing of our project presented conflicts with other activities such as hunting, fishing, and so forth. Despite their interest in the project, community members were at times unavailable to participate. In one case (Wekweeti), despite all prior communications, arrangements, and engagements with the collaborating community organization, 90 percent of the community members were unavailable during the scheduled fieldwork. To make the best use of time and resources, we documented interviews of the available members and moved on to the next community.

A few participants expressed research fatigue or "burnout" (Cullen 2010). Since the advent of the current IPY, there has been an increase in the intensity of Arctic research and interest in TEK integration with science. With the majority of fieldwork concentrated in the summer months, in each one of the six participating communities, participants commented on the overall increase in community visitations by researchers. Participants in some communities expressed annoyance over being treated as "subjects of research" where information was gathered and results and findings were not reported back. In some cases, similar research projects were being carried out simultaneously by different universities or agencies. The Voices Project's use of videography was perceived by participants as a relatively refreshing mode of interviewing, over conventional methods, with some participants expressing enjoyment in "being on-screen." Our written commitment to send all materials back to the communities and each participant also seemed to alleviate issues of "take-it-and-leave" research approaches and research fatigue. We have received supportive inquiries from the participants since starting the project, expressing their curiosity about the project's progress, which is another indicator of successful engagement with the participants.

\section{Communication of the communities' LK and outreach}

Achieving successful stewardship of social-ecological systems has been linked to documenting, integrating, and using LK in monitoring, research, and policy making (Berkes and Folke 1998, Folke 2004, Chapin et al. 2009). These linkages have been found in many cases to contribute to the adaptive capacity of systems (Armitage et al. 2007). Although theoretically elegant as an idea, realizing this goal in practice is a significant challenge. In part, this challenge is related to the historical conflict in management and governance of human-rangifer systems attributable to the dominance of the science-based epistemological perspective over indigenous systems and the limited trust of indigenous people in the government agencies directing resource management (Freeman 1989, Urquhart 1989, Klein 1991). Although the settlement of land claims and the establishment of comanagement arrangements have opened the door for greater interactions between parties, operationalizing the ideas of integration remains problematic (Kofinas 2005). The Voices Project sought to provide a platform for indigenous perspectives within the context of CARMA without fragmentation and interpretation of results by third parties. The full collection of videos from individual interviews and the composite short features exposed nonindigenous perspectives to aspects of the Caribou People's lives, ranging from understandings on caribou ecology to community challenges related to the intergenerational transfer of traditional knowledge. This approach, therefore, served as a test to explore how creating such a space would complement the greater CARMA effort and interests among communities of the Caribou People.

Videos provide a powerful means of communication and form of outreach to other communities. As Branch (2011) found, participatory videography is empowering to the community members because the visual component puts emphasis on them, i.e., the one who is telling the story. Video presents points of view/ opinions and beliefs as a form of bearing witness and making a testimony. This process transforms the presentation of experiences to a wider public as a form of political action (Rodriguez 2001). Participants in these isolated communities looked at the Voices Project as an opportunity to connect with other indigenous communities and a gateway for social and political exchanges among them. The leaders in all six participating communities recorded extensive interviews and identified their statements combined with visual images to be a powerful message to reach out to policy makers and the greater public. In this respect, the project was successful in giving the Caribou People another voice in today's multidimensional socialpolitical milieu.

Traditional knowledge is the intellectual property of the knowledge holder and the community; often there is a tension 
about what and how much can be shared with outsiders and who should have access to it (Huntington 2000). Northern Canadian communities that are in the process of land-claim settlements and have information pertaining to traditional hunting areas have concerns about what information is available publicly and how that information could affect settlement procedures. These communities with limited power and capacity are dealing with significant political maneuvering and challenges. For them, the decision to participate in the Voices Project and how much information to disclose publicly was beyond the IPY agenda. We were cognizant of this issue, and wherever necessary, the videotaped content was reviewed by the community leaders before it was included in the project's information base.

There is also an epistemological dilemma pertaining to the appropriateness of interpreting knowledge and the translation of LK without consideration of its source and location. In doing so, there is a danger that the researcher or interpreter might construct, deconstruct, and reconstruct another's knowledge (Rosenstein 2002). This problem is especially pertinent to video data because video as a medium can be more intrusive and more open to abuse than other research methods; there is a risk of the information being manipulated through editing or being taken out of context and presented, which can change its entire meaning. An important characteristic of the Voices Project was to tell the stories of people with their own voices and without any modifications or abbreviations. Although reviewing the project's objectives and methods with participants a priori, the Caribou People described this aspect of the project as important and expressed satisfaction in not being treated as subjects of research but rather having their voices presented without alteration.

\section{Sharing of the Voices Project by making the videos freely} accessible in the public domain

The issue of data ownership is complex in all research, and even more so with the data collected through the participatory process or videotaped intellectual property (Albrecht 1985, Rosenstein 2002). Do the videotaped data belong to the subject of the video or to the researcher? The participants or the researcher may want to use the video for documentation, publicity, fund-raising, or other purposes. Where should the resultant video product be shown? Can the researcher show it at will to colleagues at conferences or to students during lectures? In the Voices Project, these questions were addressed a priori, and an agreement was reached with participants on how and where the data would be used and distributed. A basic understanding to which all agreed was that all information would be made freely available to the public via the Internet.

\section{Additional methodological and philosophical challenges}

\section{The technical challenges of filmmaking}

Filmmaking is a time- and effort-intensive process; filmmaking in collaboration with communities makes it even more so (Barbash and Taylor 1997, Stiegman and Pictou 2010). If the process is too slow, there may be a loss of interest and trust from collaborating organizations; if the process is too fast, there can be questions of trust from community representatives. Time and funding constraints of researchers limit the engagement with participants. Language differences required translators in some communities, which were sometimes difficult to find. Cargo and Mercer (2008) also highlighted time and funding limitations as an important source of challenges in doing participatory research that include establishing and maintaining trust and respect, ensuring sufficient time to develop a partnership, and providing adequate time and resources to the collaboration.

Relevance of research products and outcomes for the participants Evans and Foster (2009) note that despite the popularity of videography in community-participatory research, there has been a lack of creation and distribution of research products that are relevant, inclusive, and accessible to the communities. In the Voices Project, we created video-based resources and products that the community members found useful and made efforts to bring the products back to the communities. The Voices Project was successful in overcoming this problem of relevance. We produced short films and websites, performed screenings at various national and international venues including film festivals and scientific conferences, and have been distributing the material widely to other Arctic communities and outreach centers free of cost.

\section{The limitations of participants' involvement in every step}

In the case of video-based research, it is challenging to maintain participation across all phases of the production process. Depending on the project objectives or participants' skills, it may neither be necessary nor desirable to involve participants at all levels. In the Voices Project, participation did not extend to the editing phase, in part because of the geographic spread of communities and the budgetary limitations of being inclusive in this phase. Editing can be challenging because of technical complexities and logistical difficulties. Involvement in this phase would also have diverted participants from their other priorities, e.g., subsistence activities. Community members, especially youth who expressed interest in learning, were included in the videography process and were provided the opportunity and some training to use the camera.

\section{Integration of the Voices Project into the wider CARMA research agenda}

Our primary objective was to facilitate intercommunity communication and to extend this communication to noncommunity members, e.g., researchers and agency personnel. Communities wanted to learn from each other, so we started a process of documentation and sharing between communities. The communication with researchers was largely an indirect benefit. These direct and indirect effects of the Voices Project for the CARMA network are significant in the long-term because of the development of new trust and communication relationships between indigenous communities and CARMA researchers. Indigenous people took the leading role in this process, allowing for local voices to be represented along with science in a more holistic manner. In other words, this project provided a broad stage on which the Caribou People's perspectives were articulated, documented, presented, and archived for the future. The Voices Project was one of the main research initiatives of CARMA, and in that way elevated the legitimacy of the CARMA network for both caribou researchers and the Caribou People.

\section{CONCLUSION}

We have described the methodology of the Voices Project. We successfully accomplished the three goals set by the participating communities through the application of our participatory 
videography, which overcame the primary challenges we had identified in documentation and sharing of traditional knowledge (Table 1).

To date, the project has documented the perspectives of the Caribou People from six different communities of North America and facilitated communication and sharing of this information with other communities, scientists, and the general public. As a partnership with communities, the project portrayed the Caribou People and their changing world through their own experiences and stories. The information gathered through interactions in each community provides insights on the range of issues being faced by people in different villages and will contribute to the discussion about the effects of environmental and social changes on caribou as well as people who subsist on caribou. The project continues as an ongoing effort through use of the Internet. We envision this project as becoming an ongoing legacy, where more communities join in and share their voices and experiences by creating and posting their own videos.

The participants of the Voices Project found video to be a useful tool for several reasons. The elders in most communities said that stories captured on videos would be their legacy for the communities after they pass on. These videos would serve their people as a repository of traditional ways in changing times. The videos were acknowledged to be an effective outreach and educational tool by the elders and leaders. These communities looked at the Voices Project as a potential way of connecting with other indigenous communities and a gateway for social and political exchanges among them. From a methodological perspective, we found that only through active participation of the community members were the most notable challenges overcome. Nevertheless, several issues we raise still require care and commitment to this type of work, as is the case with any culturally sensitive ethnography.

The outcome of this project is a web interface, which is in progress through which all the interviews will be shared in the public domain. The Voices Project is also important in its international scope. On the one hand, barren-ground caribou may be transboundary in nature, and on the other hand, the issues facing the Caribou People are shared, irrespective of political boundaries. The Voices Project was one mechanism to overcome transboundary issues.

The approach and findings of this project may inform scientists and wildlife managers seeking to develop stewardship strategies and foster community resilience in times of rapid change. By incorporating LK and perspectives in scientific research, and in cooperation with the caribou users, scientists and wildlife managers are better able to support community efforts toward adaptation and sustainability. Local voices enhance local adaptive capacity through helping to document and share the invaluable knowledge and experiences of the communities among the Caribou People and the greater world. The outcomes of this project and the model of using videography that it provides have contributed to a holistic understanding of change and therefore to promoting the adaptive capacity of these northern communities.

Responses to this article can be read online at: http://www.ecologyandsociety.org/issues/responses. php/6327

\section{Acknowledgments:}

Voices of the Caribou People project was funded by the CircumArctic Rangifer Monitoring and Assessment (CARMA) network through the Canadian International Polar Year program. Archana Bali received funding from the George Schaller Fellowship through the Liz Claiborne and Art Ottenberg Foundation (New York, USA), Yukon College (Whitehorse, Yukon, Canada), and the U. S. National Science Foundation (OPP Project \#0531200, "Heterogeneity and Resilience of Human-Rangifer Systems: A Circumpolar Social-Ecological Synthesis" project). We are thankful to the people of Anaktuvuk Pass, Old Crow, Wekweeti, LutselK'e, Arviat, and Kawawachikamach for sharing their views and stories with us and making this a successful collaboration. We also thank Dr. Martin Robards (Wildlife Conservation Society) for input on drafts of the manuscript, and Drs. Robert White, Donald Russell, Anne Gunn, and David McGuire for their support and encouragement throughout the project.

\section{LITERATURE CITED}

Albrecht, G. L. 1985. Videotape safaris: entering the field with a camera. Qualitative Sociology 8:325-344.

Arctic Climate Impact Assessment (ACIA). 2004. Impacts of a warming Arctic: Arctic climate impact assessment. Cambridge University Press, Cambridge, UK.

Armitage, D., F. Berkes, and N. Doubleday, editors. 2007. Adaptive co-management: collaboration, learning, and multi-scale governance. University of British Columbia Press, Vancouver, British Columbia, Canada.

Bali, A., and G. Kofinas. 2008. Voices of the Caribou People. Conservation of Arctic Flora and Fauna (CAFF), Akureyri, Iceland. [online] URL: http://voicesproject.caff.is/

Barbash, I., and L. Taylor. 1997. Cross-cultural filmmaking: a handbook for making documentary and ethnographic films and videos. University of California Press, Berkeley, California, USA.

Bateson, G., and M. Mead. 1952. Trance and dance in Bali [film]. Stock\# 24636DVD, format DVD (anthropology), 22 minutes. Penn State Media, University Park, Pennsylvania, USA.

Berkes, F. 2012. Sacred ecology: traditional ecological knowledge and resource management. Third edition. Taylor and Francis, Philadelphia, Pennsylvania, USA.

Berkes, F., J. Colding, and C. Folke. 2000. Rediscovery of traditional ecological knowledge as adaptive management. Ecological Applications 10:1251-1262. http://dx.doi.org/10.1890/1051-0761 (2000)010[1251:ROTEKA]2.0.CO;2

Berkes, F., and C. Folke. 1998. Linking social and ecological systems for resilience and sustainability. Pages 1-26 in F. Berkes and C. Folke, editors. Linking social and ecological systems: management practices and social mechanisms for building resilience. Cambridge University Press, New York, New York, USA.

Branch, M. J. 2011. Participatory video as a research method for better understanding community forestry: a case study. Pages 68-75 in S. Phuntsho, K. Schmidt, R. Kuyakanon, and K. J. Temphel, editors. Community forestry in Bhutan: putting people at the heart of poverty reduction. Ugyen Wangchuck Institute for 
Conservation and Environment and Social Forestry Division, Jakar and Thimphu, Bhutan. [online] URL: https://assets. helvetas.ch/downloads/2011 phuntsho et al eds bhutan of poverty reduction.pdf

Cargo, M., and S. L. Mercer. 2008. The value and challenges of participatory research: strengthening its practice. Annual Review of Public Health 29:325-350. http://dx.doi.org/10.1146/annurev. publhealth.29.091307.083824

Chalfen, R. 2011. Differentiating practices of participatory visual media communication. Pages 186-200 in E. Margolis and L. Pauwels, editors. The SAGE handbook of visual research methods. SAGE, Thousand Oaks, California, USA.

Chapin, F. S., G. P. Kofinas, and C. Folke, editors. 2009. Principles of ecosystem stewardship: resilience-based natural resource management in a changing world. Springer-Verlag, New York, New York, USA.

Cruikshank, J. 1998. The social life of stories. University of Nebraska Press, Omaha, Nebraska, USA.

Cruikshank, J. 2001. Glaciers and climate change: perspectives from oral tradition. Arctic 54:377-393. http://dx.doi. org/10.14430/arctic795

Cullen, B. 2010. Conducting a participatory video project with farmers involved in the Fodder Adoption project activities in Mieso Woreda, Ethiopia: report on a short consultancy. International Livestock Research Institute, Nairobi, Kenya. [online] URL: http://cgspace.cgiar.org/bitstream/handle/10568/2700/ $\underline{B C R e p o r t P V F A P M i e s o . p d f ? \text { sequence }=1}$

Evans, M., and S. Foster. 2009. Representation in participatory video: some considerations from research with Métis in British Columbia. Journal of Canadian Studies 43:87-108.

Flaherty, R. J. 1922. Nanook of the North [film]. Criterion Collection Spine \#33, format $33 \mathrm{~mm}$, black and white, silent, 75 minutes. Criterion Collection, New York, New York, USA.

Folke, C. 2004. Traditional knowledge in social-ecological systems. Ecology and Society 9(3): 7. [online] URL: http://www. ecologyandsociety.org/vol9/iss3/art7/

Freeman, M. 1989. Graphs and gaffs: a cautionary tale on the common property resource debate. Pages 92-109 in F. Berkes, editor. Common property resources; ecology and community-based sustainable development. Belhaven, London, United Kingdom.

Gearheard, S. 2005. Using interactive multimedia to document and communicate Inuit knowledge. Inuit Studies 29:91-114. http:// dx.doi.org/10.7202/013934ar

Gunn, A., D. Russell, and J. Eamer. 2011. Northern caribou population trends in Canada. Canadian Biodiversity: Ecosystem Status and Trends 2010, Technical Thematic Report No. 10. Canadian Councils of Resource Ministers. Ottawa, Ontario, Canada. [online] URL: http://www.speciesatrisk.ca/resource/ DOCUMENT/8218No.10 Northern Caribou Feb\%202012 E. pdf

Hartman, G. 1994. Holocaust remembrance. Blackwell, Oxford, United Kingdom.

Huntington, H. P. 1998. Observations on the utility of the semidirective interview for documenting traditional ecological knowledge. Arctic 51:237-242. $\underline{\text { http://dx.doi.org/10.14430/ }}$ arctic1065

Huntington, H. P. 2000. Using traditional ecological knowledge in science: methods and applications. Ecological Applications 10:1270-1274. http://dx.doi.org/10.1890/1051-0761(2000)010[1270: UTEKIS]2.0.CO;2

Israel, B. A., A. J. Schultz, E. A. Parker, and A. B. Becker. 1998. Review of community-based research: assessing partnership approaches to improve public health. Annual Review of Public Health 19:173-202. http://dx.doi.org/10.1146/annurev.publhealth.19.1.173

Kassi, T. 2001. Our history that binds us [film]. Format DVD (oral history). Vuntut Gwitchin First Nation, Old Crow, Yukon, Canada.

Klein, D. R. 1991. Caribou in the changing North. Applied Animal Behaviour Science 29:279-291. http://dx.doi.org/10.1016/0168-1591 (91)90254-U

Kofinas, G. P. 2005. Caribou hunters and researchers at the comanagement interface: emergent dilemmas and the problem of legitimacy in power sharing. Anthropologica 47:179-196.

Krupnik, I. 2009. "The way we see it coming": building the legacy of indigenous observations in IPY 2007-2008. Pages 129-142 in I. Krupnik, M. A. Lang, and S. E. Miller, editors. Smithsonian at the poles: contributions to International Polar Year science. Smithsonian Institution Scholarly, Washington, D.C., USA. http://dx.doi.org/10.5479/si.097884601X.11

Kunuk, Z. 2001. Atanarjuat the fast runner [film]. Format DVD (drama), 172 minutes. Isuma Productions/National Film Board of Canada, Igloolik, Nunavut, Canada.

Kunuk, Z., and I. Mauro. 2010. Inuit knowledge and climate change [film]. Format DVD (Inuit knowledge). Isuma Productions, Igloolik, Nunavut, Canada.

Lipset, D. 1982. Gregory Bateson: the legacy of a scientist. Beacon, Boston, Massachusetts, USA.

Lunch, N., and C. Lunch. 2006. Insights into participatory video: a handbook for the field. Insightshare, Oxford, United Kingdom. [online] URL: http://insightshare.org/sites/insightshare.org/files/ file/Insights $\% 20$ into $\% 20$ Participatory $\% 20$ Video $\% 20-\% 20 \mathrm{~A} \%$ 20Handbook $\% 20$ for $\% 20$ the $\% 20$ Field $\% 20$ (English)(1).pdf

Lynagh, M. 2010. Using video in community health advocacy: critical review of a participatory workshop with Breastfeeding Patrol, Mandaluyong City, Manila. Thesis, Oxford Brookes University, Oxford, United Kingdom.

Moerlein, K. J., and C. Carothers. 2012. Total environment of change: impacts of climate change and social transitions on subsistence fisheries in northwest Alaska. Ecology and Society 17 (1): 10. http://dx.doi.org/10.5751/ES-04543-170110

Moller, H., F. Berkes, P. O. Lyver, and M. Kislalioglu. 2004. Combining science and traditional ecological knowledge: monitoring populations for co-management. Ecology and Society 9(3): 2. [online] URL: http://www.ecologyandsociety.org/vol9/ iss $3 /$ art 2

Moses, M. J. 2001. Drymeat making [film]. Format DVD (oral history). Vuntut Gwitchin First Nation, Old Crow, Yukon, Canada. 
Moses, M. J., and Kassi, T. 2003. Imprints of our ancestors [film]. Format DVD (oral history). Vuntut Gwitchin First Nation, Old Crow, Yukon, Canada.

National Research Council (NRC). 2003. Cumulative environmental effects of oil and gas activities on Alaska's North Slope. National Academies, Washington, D.C., USA.

Prosser, J., editor. 1998. Image-based research: a sourcebook for qualitative researchers. Falmer, London, United Kingdom.

Rodriguez, C. 2001. Fissures in the mediascape. An international study of citizens' media. Hampton, Cresskill, New Jersey, USA.

Rosenstein, B. 2002. Video use in social science research and program evaluation. International Journal of Qualitative Methods $1: 22-43$.

Stiegman, M., and S. Pictou. 2010. How do you say Netuklimuk in English? Using documentary video to capture Bear River First Nation's learning through action. Pages 227-242 in A. Choudry and D. Kapoor, editors. Learning from the ground up: global perspectives on social movements and knowledge production. Palgrave Macmillan, New York, New York, USA.

Urquhart, D. 1989. History of research. Pages 95-101 in E. Hall, editor. People and caribou in the Northwestern Territories. Department of Renewable Resources, Government of Northwest Territories, Yellowknife, Northwest Territories, Canada.

Usher, P. J. 2000. Traditional ecological knowledge in environmental assessment and management. Arctic 53:183-193. http://dx.doi.org/10.14430/arctic849

Wallerstein, N., and B. Duran. 2003. The conceptual, historical and practice roots of community based participatory research and related participatory traditions. Pages 27-52 in M. Minkler and N. Wallerstein, editors. Community-based participatory research for health. Jossey-Bass/Wiley, San Francisco, California, USA. 